\title{
Residual Stress Characteristics of Functionally Gradient Materials
}

\author{
Yoshiyasu ITOH and Hideo KASHIWAYA \\ Heavy Apparatus Engineering Laboratory, Toshiba Corporation, 2-4, Suehiro-cho, Tsurumi-ku, Yokohama-shi, Kanagawa \\ 230 \\ 傾斜機能材料の残留応力特性 \\ 伊藤義康・柏谷英夫 \\ (株) 東芝重電技術研究所, 230 横浜市鶴見区末広町 2-4
}

[Received November 12, 1991; Accepted January 24, 1992]

The residual stresses of functionally gradient materials induced during the fabrication process were analyzed by comparing with two-layer composites prepared by direct bonding. Functionally gradient materials can be grouped into three classes, structurally gradation plates from the surface to the back, gradation coatings formed on the substrate, and gradation joints formed between base metals. In this paper, firstly, these three types of functionally gradient materials of stabilized zirconia/nickel-based alloy composites were chosen for finite element method analysis of residual stress distributions. It was verified that the residual stresses induced by uniform heating process could be decreased by use of the gradation techniques. Especially, the stress singularities at the edge of the interface of direct bonding composites were eliminated in case of the functionally gradient materials. Secondly, the effects of gradation size and material constants, such as Young's modulus and thermal expansion coefficients on the residual stress of the functionally gradient materials were investigated by the thermo-elastic analysis using the finite element method. It was found that the residual stresses could be effectively analyzed by application of a dimensionless parameter, which is $\sigma(1-$ $\left.\mu_{1}\right) /\left[E_{1}\left(\alpha_{1}-\alpha_{2}\right) \Delta T\right]$ ( $\sigma$ : residual stress, $\mu_{1}=\mu_{2}$ : Poisson's ratio, $E_{1}$ : Young's modulus of material 1, $\left(\alpha_{1}-\alpha_{2}\right)$ : difference in thermal expansion coefficient between materials 1 and 2, $\Delta T$ : temperature difference) in case of the functionally gradient materials. Thus, the analytical results indicated that the fabrication of large functionally gradient materials was difficult because of the increasing of the residual stresses for the same gradation thickness.

Key-words : Functionally gradient material, Residual stress, Finite element method, Structurally gradation plate, Gradation coating, Gradation joint

\section{Introduction}

Functionally gradient materials, which have the extremely reduction-ability of thermal stresses for temperature difference and/or different material constants, have been expected for system components used at the elevated temperature, such as space planes, gas turbines and fusion reactors etc. ${ }^{1)}$ The authors have attempted to develop a tungsten (W)/ copper $(\mathrm{Cu})$ gradation beam target, that the surface has been heated by a high temperature heat source (plasma, electron beam, ion beam etc.) and the backface has been forcibly cooled by a water. ${ }^{2)}$ Therefore, a sintering and infiltration technique was newly developed to fabricate the $\mathrm{W} / \mathrm{Cu}$ gradation beam target. ${ }^{3)}$ Also, a spray and HIP (Hot Isostatic Pressing) technique was newly proposed to fabricate a stabilized zirconia $\left(\mathrm{ZrO}_{2}\right) /$ type $316 \mathrm{~L}$ stainless steel(SUS316L) gradation material for the thermal barrier of fast breeder reactor (FBR) components. ${ }^{4)}$ The results showed that cracking and shivering of the functionally gradient materials were greatly influenced by residual stresses caused by the fabricarion process. Thus, a thorough understanding of the residual stress characteristics of the functionally gradient materials was considered extremely important in the development of fabrication processes as well as in the evaluation of the functionally gradient materials.

On the other hand, the authors attempt to apply ceramic coating on the surface of metal substrates by using a combined process of the plasma spraying and the HIP treatment. And, it is investigated the effects of residual stresses on the cracking behaviors of the coating components via analysis of the residual stress distribution characteristics in a ceramic coated metal plate. As a result, it was found that a residual stress could be effectively analyzed by application of a dimensionless stress parameter, which is $\sigma\left(1-\mu_{1}\right) /\left[E_{1}\left(\alpha_{1}-\alpha_{2}\right) \Delta T\right]\left(\sigma\right.$ : residual stress, $\mu_{1}=\mu_{2}$ : Poisson's ratio, $E_{1}$; Young's modulus of material 1 , $\left(\alpha_{1}-\alpha_{2}\right)$ : difference of thermal expansion coefficients between material 1 and material 2, $\Delta T$ : temperature difference).5),6)

In this study, it is attempt to investigate analytically the residual stress distribution characteristics and the cracking and shivering characteristics of the functionally gradient materials by using finite element method and the dimensionless stress parameter.

\section{Method of analysis}

Firstly, it is investigated for the analytical models used in this study. Hitherto, it is simply said that the functionally gradient materials have continuously varying material properties from one face to the another. ${ }^{7)}$ However, this representation is not al- 
ways sufficient to show the application of the functionally gradient materials. From an application viewpoint, the functionally gradient materials can be grouped into three classes as shown in Figs. 1(a), (b) and (c). Figure 1(a) shows a structurally gradation plate from the surface to the backface, which has described above. Figure 1(b) shows the structurally gradation coating, which is formed a structurally gradation layer on the substrate. Figure 1(c) shows the structurally gradation joint, which is formed a structurally gradation layer between the base materials. It might be though that these three are the basis patterns for the application of the functionally gradient materials. Also, these classification can be explained from the effect of difference of stress constraint on the structurally gradation layer. Namely, the structurally gradation plate is free from the stress constraint. However, in case of the gradation coating, the structurally gradation layer is restrained by a substrate, and in case of the gradation joint, the structurally gradation layer is restrained by base materials, which are formed at both faces of the gradation layer. It seems that the thermal (residual) stress may be extremely effected by the conditions of these stress constraint.

Figure 1 illustrates the three kinds of analysis model used in this study, which consisted of a structurally gradation layer of disk-shape that has a disk radius of $R$ and a thickness of $H$. In the analysis, thermo-elastic finite element program (the square element) was used to determine the thermal stresses produced when the functionally gradient materials, which were heated uniformly to a fabrication temperature and then cooled to room temperature (difference in temperature $\Delta T$ ), and the thermal stress determined was regarded as the residual stress. Namely, the thermal stresses in this analysis was opposite in sign but equal in absolute value to the thermal stress generated during the uniform heating at an elevated temperature. The analysis assumed that the three kinds of model were a perfect elastic body, i.e., plastic deformation was not taken into account. Since the models were symmetrical around the $Z$ axis, it was analyzed by dividing the shaded area in Fig. 2 into finite elements, which showed an exam-

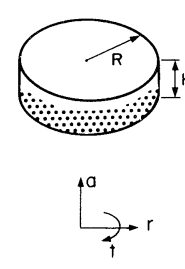

(a) Functionally gradient material

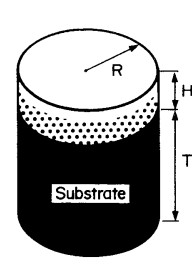

(b) Functionally gradient coating

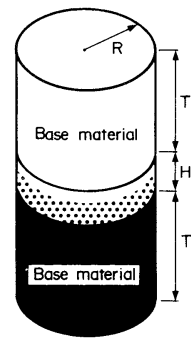

(c) Functionally gradient joint
Fig. 1. Three kind of application patterns for functionally gradient materials.

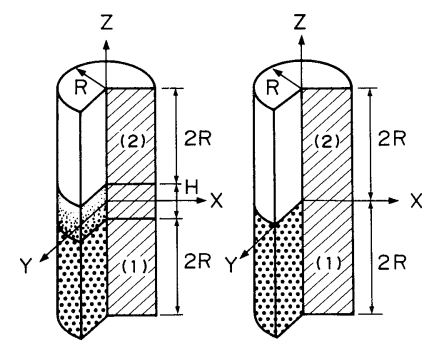

(a) Gradation $\quad$ (b) Direct

Fig. 2. Examples of analysis models for finite element method analysis, which are structurally gradation joint and direct bonding joint.

ple of the gradation joint and a direct bonding joint for comparing the residual stress characteristics.

In order to clarify the distribution characteristics of the residual stress, firstly, the functionally gradient materials of stabilized zirconia (Young's modulus; $200 \mathrm{GPa}$, Poisson's ratio; 0.3 , thermal expansion coefficient; $11 \times 10^{-6} /{ }^{\circ} \mathrm{C}$ ) / nickel based alloy (Young's modulus: $200 \mathrm{GPa}$, Poisson's ratio: 0.3, thermal expansion coefficient: $18 \times 10^{-6} /{ }^{\circ} \mathrm{C}$ ) composites were chosen for the finite element method (FEM) analysis in comparison with the direct bonding materials. Moreover, in order to clarify the effects of Young's modulus and the gradation size on the residual stresses, the analysis by the finite-element method was carried out for cases where Young's modulus ratio between material 1 and material $2, E_{2} / E_{1}=0.5,1.0,1.5$ and 2.5 and some varied cases of the gradation size between the disk diameter and gradation thicknes, $2 R / H$.

\section{Residual stress distribution characteristics}

3.1 Structurally gradation plate

Figure 3 shows the residual stress distributions calculated for heating uniformly to a fabrication tem-
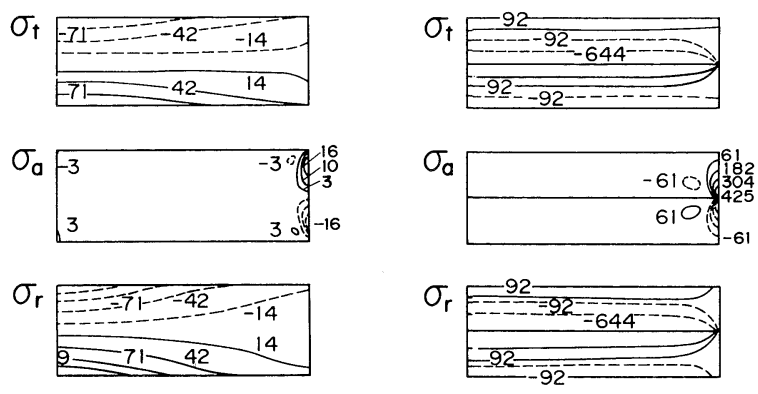

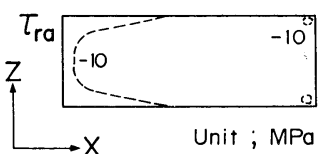

(a)

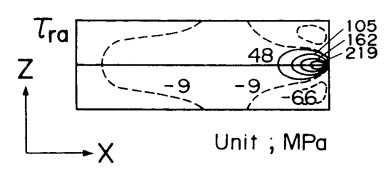

(b)
Fig. 3. Comparison of residual stress distributions of composites on the cross-section.

(a) Structurally gradation plate,

(b) Two-layer composite. 
perature and then cooling to room temperature (difference in temperature $\Delta T=1000^{\circ} \mathrm{C}$ ). Here, the analytical model size of gradation plate is a $80 \mathrm{~mm}$ diameter and a $8 \mathrm{~mm}$ thickness. The two-layer composite of a $80 \mathrm{~mm}$ diameter used for comparison is formed with the direct bonding of a $4 \mathrm{~mm}$ thick $\mathrm{ZrO}_{2}$ and a $4 \mathrm{~mm}$ thick Ni based alloy. The stress distributions per each stress component as shown in Fig. 3 are taken at the central cross section of the disk close to the edge. It was already shown by the elastic analysis that among the various stresses caused at the edges of a bonded interface between two different materials, the tensile stress component and the shearing stress component perpendicular to the interface would show singularities, and further that the stress values would diverge. ${ }^{8), 9)}$ In case of the two-layer composite, the stress components $\sigma_{\mathrm{a}}$ and $\tau_{\text {ra }}$ showed remarkable stress concentrations at the interface between two materials, as shown in Fig. 3(b). Both $\sigma_{\mathrm{a}}$ and $\tau_{\mathrm{ra}}$ decreased to zero quickly as the distance from the edge of interface increased. $\sigma_{\mathrm{t}}$ and $\sigma_{\mathrm{r}}$, each of which showed a large value at the midsection of the disk, decreased as the distance from the edge of interface decreased.

On the other hand, in case of the structurally gradation plate, it is clear that the residual stresses produced by uniform heating process decreases by using the gradation technique. Especially, the stress singularities at the edge of the bonded interface can be disappeared for eliminating the bonded interface. In this study, the tensile residual stresses, $\sigma_{\mathrm{t}}$ and $\sigma_{\mathrm{r}}$, are generated at the surface of $\mathrm{Ni}$ based alloy.

\subsection{Structurally gradation coating}

The residual stress distributions of structurally gradation coating close to the edge of interface are shown in Fig. 4(a) in comparison with the results of one-layer coating (b). Here, the analytical model size of gradation coating is a $40 \mathrm{~mm}$ diameter and a $50 \mathrm{~mm}$ thickness substrate and a $10 \mathrm{~mm}$ thickness coating film on one side, and the temperature difference for fabrication, $\Delta T$ is $1000^{\circ} \mathrm{C}$. It has been suggested, based on the elastic analysis as described the previous section, that the stress components $\sigma_{\mathrm{a}}$ and $\tau_{\text {ra }}$, while exhibiting a significant stress concentration at the edge of the bonded interface between the substrate and the coating film, decreases rapidly along the radial direction of coating film. It is also shown that $\sigma_{\mathrm{t}}$ and $\sigma_{\mathrm{r}}$ become negative in a coating layer with high thermal expansion coefficient.

On the other hand, there is a trend toward reductions in residual stresses at interface between the substrate and the coating film due to the structurally gradation. Especially, a pronounced reduction of the residual stress at the edge of the bonded interface can be observed. However, the absolute value of skin residual stresses, $\sigma_{\mathrm{t}}$ and $\sigma_{\mathrm{r}}$ at the center of coating film can not be reduced by the gradation technique. It is therefore considered that, in a coating film having a high thermal expansion coefficient relative to
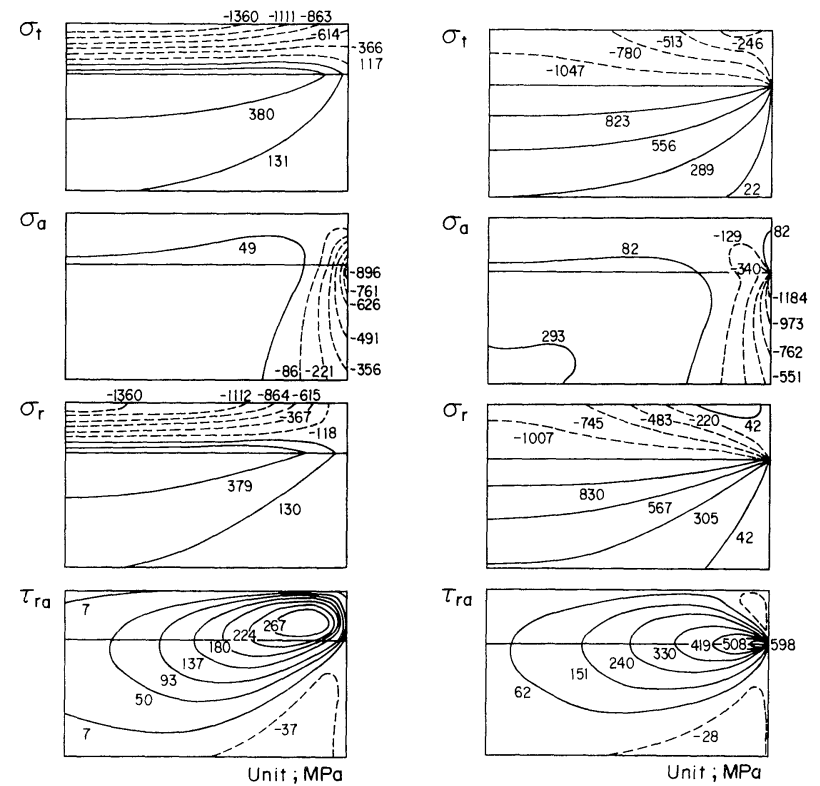

(a)

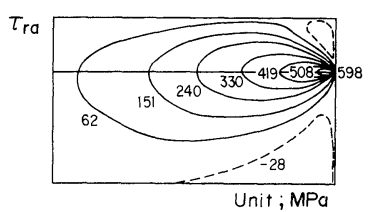

(b)

Fig. 4. Comparison of residual stress distributions of coatings on the cross-section.

(a) Structurally gradation coating,

(b) One-layer coating.
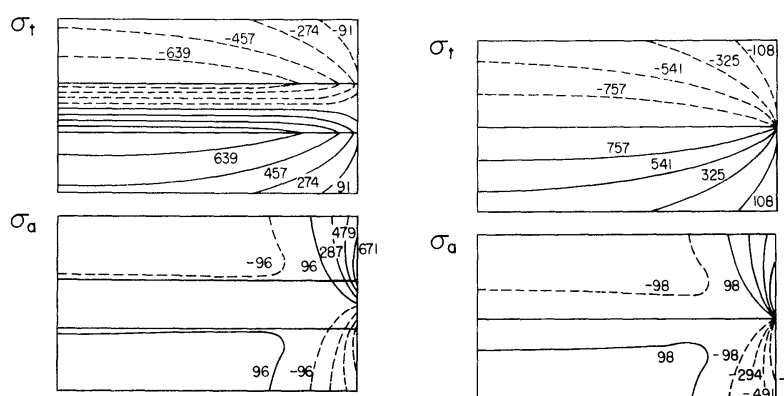

$\sigma_{\mathrm{o}}$

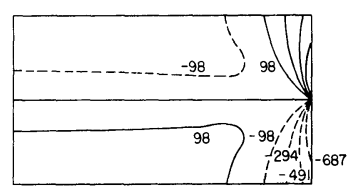

$\sigma_{\mathrm{r}}$
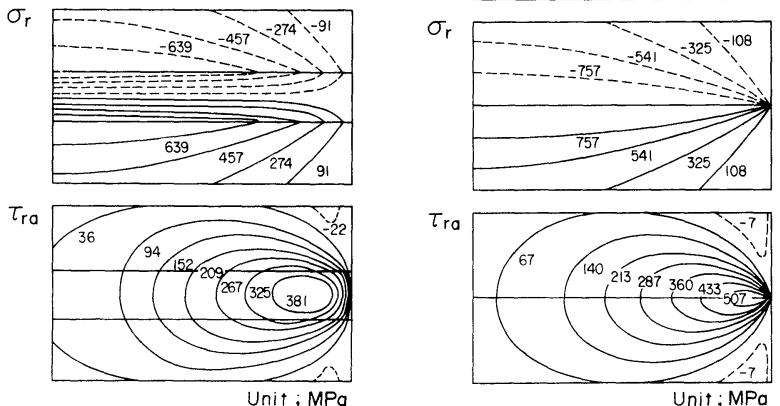

(a)

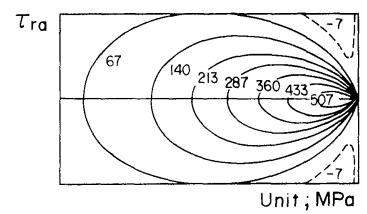

(b)

Fig. 5. Comparison of residual stress distributions of joints on the cross-section.

(a) Structurally gradation joint,

(b) Direct bonding joint.

that of the substrate, $\sigma_{\mathrm{t}}$ and $\sigma_{\mathrm{r}}$ are the major cause for the crack of the coating film.

\subsection{Structurally gradation joint}

The reduction-ability of structurally gradation joint is shown in Fig. 5(a) in comparison with the results of direct bonding joint (b). Here, the analytical model size of gradation joint is a $10 \mathrm{~mm}$ thick gradation layer between a $40 \mathrm{~mm}$ diameter and a $40 \mathrm{~mm}$ 
length base materials, and the temperature difference for fabrication, $\Delta T$ is $1000^{\circ} \mathrm{C}$. The residual stress distribution characteristics resemble those of the structurally gradation coating described the previous section. Namely, stress components $\sigma_{\mathrm{a}}$ and $\tau_{\text {ra }}$ showed stress concentrations at the interface between the base material and the gradation layer, and decreased to zero quickly as the distance from the edge of interface increased. In case of the structurally gradation joint, there is a trend toward reductions in residual stresses at interface between the substrate and the coating film due to gradation. However, it appears from the comparison of Fig. 4 and Fig. 5 that the stress reduction-ability of gradation joint at the edge of interface may not be more pronounced than that of the gradation coating. And the residual stress components, $\sigma_{\mathrm{t}}$ and $\sigma_{\mathrm{r}}$ at the central axis of the gradation joint can be reduced effectively by the gradation technique in comparison with the gradation coating.

\section{Effect of various factors on residual stresses}

\subsection{Structurally gradation plate}

It was verified that the residual stress at the bonded interface decreased by use of the gradation technique. In this section, the effects of the material constants and the gradation size on the residual stress will be investigated by means of converting the parameter to a dimensionless expression, as previously reported.5),6) From an analogical law of thermo-elasticity, the thermal (residual) stress can be represented by dimensionless parameter described below in case of $\mu_{1}=\mu_{2}$.

$$
\begin{aligned}
& \sigma\left(1-\mu_{1}\right) /\left[E_{1}\left(\alpha_{1}-\alpha_{2}\right) \Delta T\right] \\
& \quad=f\left(E_{2} / E_{1}, \mu_{1}, \text { size parameter }\right)
\end{aligned}
$$

$\sigma:$ residual stress

$\mu_{1}\left(=\mu_{2}\right):$ Poisson's ratio

$E_{1}$ : Young's modulus of material 1

$\left(\alpha_{1}-\alpha_{2}\right)$ : difference of thermal expansion coefficient between material 1 and material 2

$\Delta T:$ temperature difference

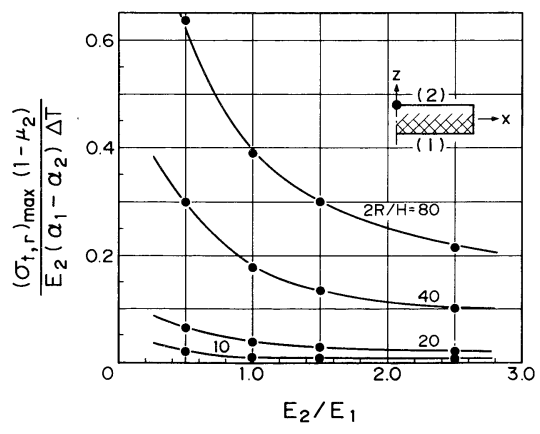

(a)
Therefore, in case of $\mu_{1}=\mu_{2}$, the thermal stress can be analyzed easily due to only one calculation for the parameter of $\alpha_{1}, \alpha_{2}$ and $\Delta T$. If this dimensionless parameter can be used in case of the functionally gradient materials, it is very useful to analyze them. Table 1 shows some examples of FEM analysis in case of the structurally gradation plate. The validity of the dimensionless parameter is well confirmed as shown in Table 1. Namely, the analogical law holds good concerning the material constants and the gradation size.

Figures 6 (a) and (b) show the effect of the gradation size, $2 R / H$ and Young's modulus ratio, $E_{2} / E_{1}$ on the maximum residual stress at the center of the plate surface using the dimensionless parameter. It is seen that the dimensionless residual stresses, $\sigma_{\mathrm{t}}, \sigma_{\mathrm{r}}$ and $\tau_{\text {ra }}$ decrease with the increase of Young's modulus ratio, $E_{2} / E_{1}$ and the decrease of the gradation size, $2 R / H$ except the stress, $\tau_{\text {ra }}$ of $2 R / H=80$. The results indicate that the dimensionless residual stress, $\tau_{\text {ra }}$ at the thickness center increases with increasing the plate diameter and Young's modulus ratio in the range of $2 R / H=10$ to 40 . And the dimensionless residual stress, $\sigma_{\mathrm{t}}$ and $\sigma_{\mathrm{r}}$ at the surface increase with increasing the plate diameter and Young's modulus ratio over $2 R / H=40$. In the case

Table 1. Verification of analogical law of thermo-elasticity,

\begin{tabular}{|c|c|c|c|c|c|c|c|}
\hline & Case I & Case II & Case III & Case IV & Case V & Case VI \\
\hline \multicolumn{2}{|c|}{$\begin{array}{l}\text { Size (mm) } \\
\text { E (GPa) } \\
\alpha \times 10^{-6}\left(/{ }^{\circ} \mathrm{C}\right) \\
\mu\end{array}$} & $\begin{array}{c}\phi 8 \times t 0.8 \\
200 \\
11 / 18 * \\
0.3\end{array}$ & $\begin{array}{c}\phi 8 \times \mathrm{t} 0.8 \\
200 \\
7 / 14 \\
0.3\end{array}$ & $\begin{array}{c}\phi 8 \times t 0.8 \\
100 \\
7 / 14 \\
0.3\end{array}$ & \begin{tabular}{|c|}
$\phi 8 \times \mathrm{t} 0.8$ \\
$170 / 100$ \\
$11 / 18$ \\
0.3 \\
\end{tabular} & \begin{tabular}{|c|}
$\phi 8 \times t 0.8$ \\
$85 / 50$ \\
$19 / 5$ \\
0.3 \\
\end{tabular} & $\begin{array}{c}\phi 16 \times t 1.6 \\
85 / 50 \\
19 / 5 \\
0.3\end{array}$ \\
\hline $\begin{array}{l}\sigma_{\mathrm{r}} \\
(\mathrm{X}=0) \\
(\mathrm{MPa})\end{array}$ & $\begin{array}{r}2 \mathrm{Z} / \mathrm{H}=0.125 \\
0.375 \\
0.625\end{array}$ & $\begin{array}{l}-0.2906 \\
-0.7950 \\
-1.055\end{array}$ & $\begin{array}{l}-0.2906 \\
-0.7950 \\
-1.055\end{array}$ & $\begin{array}{l}-0.1453 \\
-0.3975 \\
-0.5277\end{array}$ & $\begin{array}{l}-0.1312 \\
-0.5146 \\
-0.7375\end{array}$ & $\begin{array}{l}0.1312 \\
0.5146 \\
0.7375\end{array}$ & $\begin{array}{l}0.1312 \\
0.5146 \\
0.7375\end{array}$ \\
\hline $\begin{array}{l}\sigma_{a} \\
(\mathrm{X}=0) \\
(\mathrm{MPa})\end{array}$ & $\begin{array}{r}2 \mathrm{Z} / \mathrm{H}=0.125 \\
0.375 \\
0.625\end{array}$ & $\begin{array}{l}0.1715 \\
0.4563 \\
0.5547\end{array}$ & $\begin{array}{l}0.1715 \\
0.4563 \\
0.5547\end{array}$ & $\begin{array}{l}0.2282 \\
0.2774\end{array}$ & $\begin{array}{l}0.2266 \\
0.4216 \\
0.4805\end{array}$ & $\begin{array}{l}0.2266 \\
0.4216 \\
0.4805\end{array}$ & $\begin{array}{l}0.2266 \\
0.4216 \\
0.4805\end{array}$ \\
\hline $\begin{array}{c}\mathrm{v} \\
(\mathrm{Z}=0) \\
(\mathrm{mm})\end{array}$ & $\begin{array}{r}r / R=0.248 \\
0.576 \\
0.764 \\
0.874 \\
1.000\end{array}$ & $\begin{array}{l}-.006515 \\
-0.02719 \\
-0.04590 \\
-0.05904 \\
-0.07710\end{array}$ & $\begin{array}{l}-.006515 \\
-0.02719 \\
-0.04590 \\
-0.05904 \\
-0.07710\end{array}$ & $\begin{array}{l}-.006515 \\
-0.02719 \\
-0.04590 \\
-0.05904 \\
-0.07710\end{array}$ & $\begin{array}{l}-.006510 \\
-0.02715 \\
-0.04582 \\
-0.05893 \\
-0.07696\end{array}$ & $\begin{array}{l}0.01302 \\
0.05429 \\
0.09164 \\
0.1179 \\
0.1539\end{array}$ & $\begin{array}{l}0.02604 \\
0.1086 \\
0.1833 \\
0.2357 \\
0.3078\end{array}$ \\
\hline
\end{tabular}
which are some examples of FEM analysis

$(*$ Gradation of material $(2) /$ material $(1))$

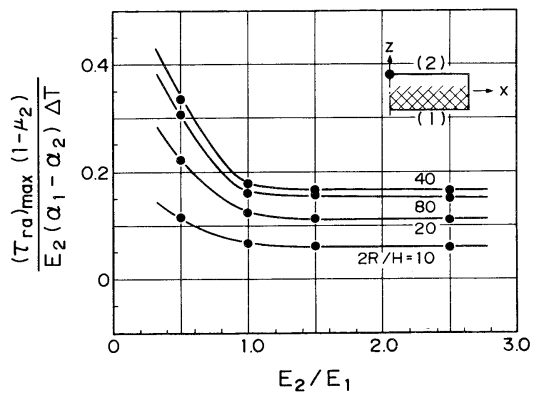

(b)

Fig. 6. Effect of gradation size and Young's modulus ratio on dimensionless residual stresses in case of structurally gradation plate.

(a) Maximum stresses, $\sigma_{\mathrm{t}}$ and $\sigma_{\mathrm{r}}$ at center of the plate,

(b) Maximum stress, $\tau_{\mathrm{ra}}$ at center of the plate. 
of small size gradation plate, $2 R / H<40$, the separation cracking are may occur. If $2 R / H>40$ then $\sigma_{\mathrm{t}}$ and $\sigma_{\mathrm{r}}>\tau_{\mathrm{ra}}$ holds, surface cracking may occur.

\subsection{Structurally gradation coating}

In case of the structurally gradation coating, there is a trend toward reductions in residual stresses at the interface. However, the absolute value of skin residual stresses, $\sigma_{\mathrm{t}}$ and $\sigma_{\mathrm{r}}$ at the center of coating film can not be reduced by the gradation technique. Figure 7 (a) shows the effect of the gradation size, $2 R / H$ and Young's modulus ratio, $E_{2} / E_{1}$ on the maximum residual stress at center of the gradation coating surface using the dimensionless parameter. It can be concluded from these results that the maximum residual stress generated in the coating surface can be easily assessed, if the gradation layer $H$ is sufficiently thin compared with the substrate diameter, as follows:

$$
\begin{aligned}
& \sigma\left(1-\mu_{1}\right) /\left[E_{1}\left(\alpha_{1}-\alpha_{2}\right) \Delta T\right]=1 \\
& \sigma=\sigma_{\mathrm{t}}=\sigma_{\mathrm{r}}, \sigma_{\mathrm{a}}=0
\end{aligned}
$$

Figures 7 (b) and (c) show the effect of the gradation size, $2 R / H$ and Young's modulus ratio, $E_{2} / E_{1}$ on the maximum residual stress near the edge of interface between the gradation coating and substrate. Also as with Fig. 7 (a), it is seen that the dimensionless residual stress decreases with the increase of Young's modulus ratio, $E_{2} / E_{1}$. However, the dimensionless residual stress decreases with the increase of the gradation size, $2 R / H$ as shown in Figs. 7 (b) and (c). This tendency is basically different from the residual stress generated in the coating surface. In the range of $100<2 R / H<800$, it is especially noted that the dimensionless residual stress generated in the coating surface shows a high stress value in comparison with the stress near the edge of the coating interface.

\subsection{Structurally gradation joint}

The maximum residual stresses, $\sigma_{\mathrm{a}}, \sigma_{\mathrm{t}}$ and $\sigma_{\mathrm{r}}$ generated at the central axis are shown in Figs. 8(a) and (b) by converting the parameter to a dimension-

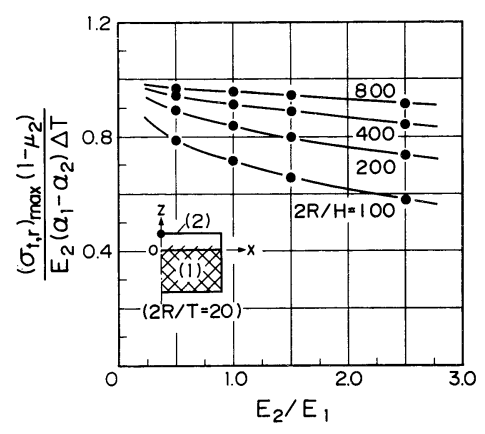

(a)

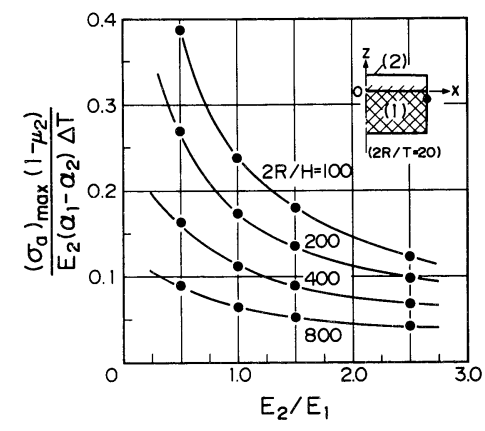

(b)

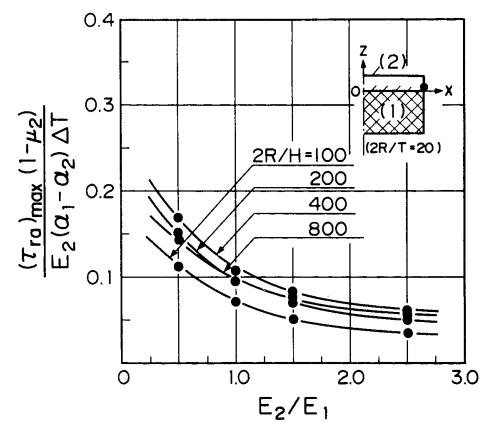

(c)

Fig. 7. Effect of gradation size and Young's modulus ratio on dimensionless residual stresses in case of structurally gradation coating.

(a) Maximum stresses, $\sigma_{\mathrm{t}}$ and $\sigma_{\mathrm{r}}$ at the coating center,

(b) Maximum stress, $\sigma_{\mathrm{a}}$ at the coating edge,

(c) Maximum stress, $\tau_{\text {ra }}$ at the coating edge.

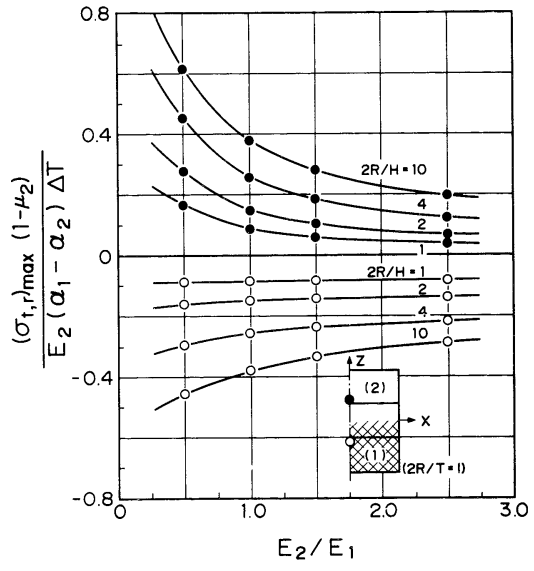

(a)

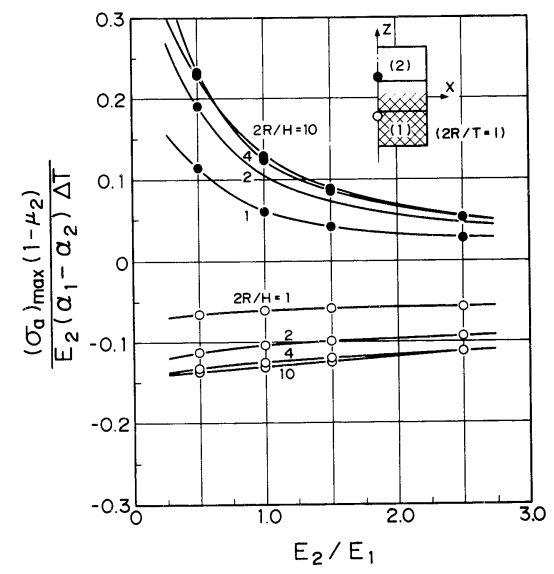

(b)

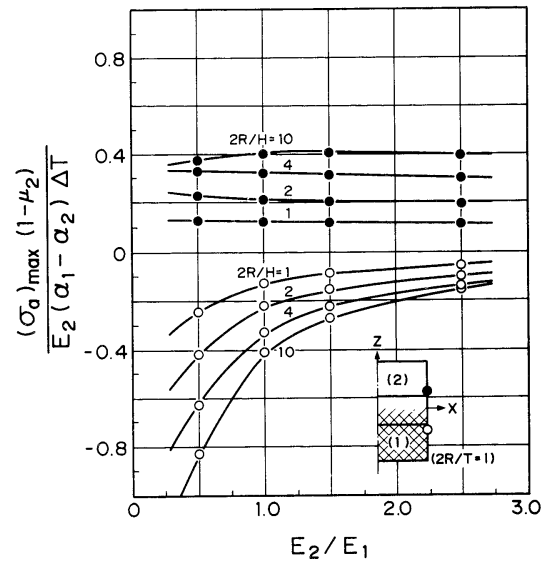

(c)

Fig. 8. Effect of gradation size and Young's modulus ratio on dimensionless residual stresses in case of structurally gradation joint.

(a) Maximum stresses, $\sigma_{\mathrm{t}}$ and $\sigma_{\mathrm{r}}$ at the central axis,

(b) Maximum stress, $\sigma_{\mathrm{a}}$ at the central axis,

(c) Maximum stress, $\sigma_{\mathrm{a}}$ at the joint edge. 
less expression. In this case, it is seen that the dimensionless residual stress decreases with the increase of Young's modulus ratio, $E_{2} / E_{1}$ and the decrease of the gradation size, $2 R / H$. Also, the maximum residual stress, $\sigma_{\mathrm{a}}$ generated at the edge of gradation joint shown in Fig. 8 (c). In the range of $1<2 R / H<10$, the residual stress, $\sigma_{\mathrm{a}}$ generated at the edge of gradation joint is nearly constant regarding Young's modulus ratio, $E_{2} / E_{1}$. However, the maximum residual stress, $\sigma_{\mathrm{a}}$ generated at the edge of gradation joint decreases with the decrease of the gradation size, $2 R / H$. In this analysis, the relation of maximum residual stress, $\sigma_{\mathrm{a}}<\sigma_{\mathrm{t}}$ and $\sigma_{\mathrm{r}}$ is realized at the central axis. And, the maximum residual stress, $\sigma_{\mathrm{a}}$ generated at the edge of gradation joint is greater than the stress, $\sigma_{\mathrm{t}}$ and $\sigma_{\mathrm{r}}$ generated at the central axis in case of $E_{2} / E_{1}>1$. If $E_{2} / E_{1}<1$, the relation, $\sigma_{\mathrm{a}}<\sigma_{\mathrm{t}}$ and $\sigma_{\mathrm{r}}$ is realized. Therefore, in the case $E_{2} / E_{1}>1$, circumferential cracks are predicted at the surface near the interface between base materials and the gradation layer. If $E_{2} / E_{1}<1$, internal longitudinal cracks are predicted at the interface between base materials and the gradation layer.

\section{Conclusions}

(1) It was proposed that the functionally gradient materials could be grouped into three classes from an application viewpoint. They are the structurally gradation plate, the structurally gradation coating and the structurally gradation joint.

(2) The reduction-ability of thermal stress was investigated using FEM thermo-elastic analysis. It was verified that the stress singularities at the edge of the interface of direct bonding composites could be disappeared by the gradation technique.

(3) The effects of the gradation size and material constants on the residual stress were investigated using FEM thermo-elastic analysis. In case of the functionally gradient materials, it was found that the residual stress could be effectively analyzed by application of the dimensionless parameter, which is $\sigma\left(1-\mu_{1}\right) /\left[E_{1}\left(\alpha_{1}-\alpha_{2}\right) \Delta T\right]$.

(4) The dimensionless residual stress of the functionally gradient materials decreases with the increase of Young's modulus ratio, $E_{2} / E_{1}$ and the decrease of the gradation size, $2 R / H$. However, the dimensionless residual stress at the surface of structurally gradation coating surface increases with the the decrease of the gradation size, $2 R / H$.

\section{References}

1) Y. Itoh, M. Takahashi, H. Kashiwaya, H. Takano, N. Tachikawa and S. Adachi, Nuclear Engineering, 37, 59-65 (1991).

2) M. Takahashi, Y. Itoh and H. Kashiwaya, Proc. the 1st Int. Sympo. on FGM (1990) pp. 129-34.

3) Y. Itoh, M. Takahashi and H. Kashiwaya, Proc. the 10th HIP Seminar (1990) pp. 14-20.

4) M. Takahashi, Y. Itoh, M. Miyazaki, H. Kashiwaya and S. Adachi, Proc. the 4th Sympo. on FGM (1991) pp. 137-41.

5) Y. Itoh, Y. Ishiwata and H. Kashiwaya, J. of Ceramic Society of Japan, Int. Edition, 97, 734-40 (1989).

6) Y. Itoh and H. Kashiwaya, J. of the Ceramic Society of Japan, Int. Edition, 98, 1246-53 (1991).

7) M. Sasaki and T. Hirai, Seramikkusu Ronbunshi, 99, 1002-13 (1991).

8) D. B. Bogy, Int. J. Solids Structure, 6, 1287-313 (1970).

9) V. L. Hein and F. Erdogan, Int. J. Fracture Mechanics, 7, 317-30 (1971). 